\title{
The Role of Tropical Mean-State Biases in Modeled Winter Northern Hemisphere El Niño Teleconnections
}

\author{
SAMANTHA FERRETT AND MATTHEW COLLINS \\ College of Engineering, Mathematics and Physical Sciences, University of Exeter, Exeter, United Kingdom \\ HONG-Li REN \\ Laboratory for Climate Studies and CMA-NJU Joint Laboratory for Climate Prediction Studies, National Climate Center, \\ China Meteorological Administration, Beijing, and Department of Atmospheric Science, School of Environmental Studies, \\ China University of Geoscience, Wuhan, China \\ Bo Wu \\ LASG, Institute of Atmospheric Physics, Chinese Academy of Sciences, Beijing, China \\ TIANJUN ZHOU \\ LASG, Institute of Atmospheric Physics, Chinese Academy of Sciences, and University of Chinese Academy of Sciences, \\ Beijing, China
}

(Manuscript received 6 September 2019, in final form 6 January 2020)

\begin{abstract}
The role of tropical mean-state biases in El Niño-Southern Oscillation teleconnections in the winter Northern Hemisphere is examined in coupled general circulation models from phase 5 of the Coupled Model Intercomparison Project (CMIP5). The main North Pacific teleconnection pattern, defined here by the strengths of the anomalous Kuroshio anticyclone and North Pacific cyclone, is linked to two anomalous Rossby wave sources that occur during El Niño: a negative source over East Asia and a positive source to the west of the North Pacific. Errors in the teleconnection pattern in models are associated with spatial biases in mean atmospheric ascent and descent and the strength of the corresponding forcing of Rossby waves via suppressed or enhanced El Niño precipitation responses in the tropical western North Pacific (WNP) and the equatorial central Pacific (CP). The WNP El Niño precipitation response is most strongly linked to the strength of the Kuroshio anticyclone and the CP El Niño precipitation response is most strongly linked to the strength of the North Pacific cyclone. The mean state and corresponding El Niño precipitation response can have seemingly distinct biases. A bias in the WNP does not necessarily correspond to a bias in the CP, suggesting that improvement of biases in both tropical WNP and equatorial CP regions should be considered for an accurate teleconnection pattern.
\end{abstract}

\section{Introduction}

El Niño-Southern Oscillation (ENSO) is a dominant mode of interannual variability, modulated by oceanatmosphere processes, in the equatorial Pacific. ENSO events have been shown to have a large impact on weather worldwide, such as East Asia (e.g., Zhang et al. 1996, 1999; Wang et al. 2000; Wang and Chan 2002;

Corresponding author: Samantha Ferrett, s.j.ferrett@reading. ac.uk
Ashok et al. 2007; Wu et al. 2009; Xie et al. 2009; Kug et al. 2010; Zhang et al. 2016b), North America (e.g., Wallace and Gutzler 1981; Horel and Wallace 1981; Ashok et al. 2007), and the Atlantic (e.g., Klein et al. 1999; Giannini et al. 2000).

Rainfall in East Asia is linked to ENSO via the formation and decay of anomalous anticyclones over the western North Pacific (WNP) during the ENSO warm phase, El Niño. An anticyclone in the lower troposphere begins to form over the Philippine Sea in the late fall and persists into the subsequent summer (Wang and Zhang 
2002; Wu et al. 2017), suppressing the northerly winds along the coast of East Asia and weakening the East Asia winter monsoon (Zhang et al. 1996; Tomita and Yasunari 1996; Liren et al. 1997; J.-W. Kim et al. 2017). It has been suggested that suppressed convective heating over the west Pacific results in the anticyclone (Zhang et al. 1996; Wang et al. 2000; see also Li et al. 2017 for a review). However, the Philippine Sea anticyclone is most strongly associated with subtropical rainfall changes in East Asia, and cannot readily explain the ENSO-Asia teleconnections farther north.

A study by Son et al. (2014) suggests that East Asia rainfall, such as that in the Korean Peninsula, during El Niño is a result of an anomalous anticyclone that forms farther north around $35^{\circ} \mathrm{N}$ in early winter and decays in late winter, termed the Kuroshio anticyclone. The formation and decay of the Kuroshio anticyclone is suggested to be a result of competing effects of positive precipitation anomalies over the equatorial central Pacific (CP) that are associated with an anomalous cyclone in the North Pacific, and negative precipitation anomalies in the tropical WNP that contribute to the development of the Kuroshio anticyclone (Son et al. 2014; S. Kim et al. 2017). However, the relative strengths of $\mathrm{CP}$ and WNP precipitation responses are well captured in only a few of the CMIP5 models (S. Kim et al. 2017). Such precipitation response biases can be linked to sea surface temperature anomaly (SSTA) biases (i.e., Ham and Kug 2015). Despite improvement in the most recent generation of coupled climate models from phase 5 of the Coupled Model Intercomparison Project (CMIP5; Taylor et al. 2012), there is still a large range of modeled ENSO teleconnection behaviors (Weare 2013), creating a source of uncertainty in model projections of ENSO teleconnections in a future climate (e.g., Perry et al. 2017). The biases in underlying atmospheric responses that link the precipitation anomalies to the formation of the Kuroshio anticyclone and North Pacific cyclone, and possible reasons for precipitation anomaly bias, have not yet been closely examined.

Here we address the role of the mean-state biases in such atmospheric responses to El Niño in CMIP5. It is known that the climate mean state can play a role in the ability of a climate model to reproduce observed atmospheric responses in the equatorial Pacific that occur during El Niño events (e.g., Kim et al. 2013; Song and Zhou 2014; Ham and Kug 2015; Ferrett and Collins 2016; Ferrett et al. 2017, 2018; Bayr et al. 2018). The common equatorial Pacific cold sea surface temperature (SST) bias in coupled climate models is also known to be linked to biases in ENSO teleconnections to California and the East Asian summer monsoon (Bayr et al. 2019; Feng et al. 2018; Wang et al. 2019). Furthermore, Wu et al. (2017) suggest that the location of the mean ITCZ is pivotal to the observed formation of negative precipitation anomalies over the tropical WNP in late autumn that are subsequently associated with the Philippine Sea anticyclone. They state that the background condition is a "necessary condition" while the cold SSTAs over the WNP are a "supplemental condition." Zhang et al. (2016a) also showed in a single model study that the presence of the SST annual cycle is crucial when replicating the ENSO teleconnection to East Asia. Therefore, it seems likely that biases in the equatorial Pacific climatology in the CMIP5 models will have implications for the atmospheric responses that are thought to drive the Northern Hemispheric ENSO teleconnection. Increased understanding of teleconnection bias and links to the climatology will highlight areas of focus in future model development and will also improve confidence in future projections.

While previous studies have focused on the role of SSTs in the ENSO teleconnection, this study aims to highlight the dynamical relationships between Northern Hemisphere El Niño atmospheric teleconnection biases and the modeled Pacific atmospheric mean state in CMIP5. Corresponding biases in the underlying Rossby wave responses that link precipitation responses relatively near the equator to the Kuroshio anticyclone and North Pacific cyclone are also examined. The North Pacific cyclone is typically referred to as part of the Pacific-North America pattern (PNA; e.g., Wallace and Gutzler 1981; Horel and Wallace 1981); however, this study is primarily focused on the tropical Pacific responses associated with the forcing of such pattern, and so this is simply referred to as the North Pacific cyclone throughout. Section 2 outlines the CMIP5 and reanalyses data used in the study, and the methods are described in section 3. Results are given in section 4, with the ENSO atmospheric responses examined in section 4a. The role of the background state in tropical Pacific precipitation responses and teleconnection patterns outlined in section $4 \mathrm{~b}$. The link between ENSO precipitation responses and the formation of anomalous anticyclones and cyclones is discussed in section 4c. A summary and discussion of results is given in section 5 .

\section{Data}

\section{a. CMIP5}

The analysis uses 43 coupled climate models from the World Climate Research Programme (WCRP) CMIP5 models (Taylor et al. 2012). Further details of the models used are given in Table 1. Fields that are used are sea surface temperatures (SST), precipitation $(P)$, 
TABLE 1. CMIP5 (Taylor et al. 2012) model names. Superscripts indicate if a model belongs to one of the four model subgroups defined in the text: 1-WNPstrong; 2-WNPweak; 3-WPstrong; 4-WPweak.

\begin{tabular}{|c|c|c|}
\hline No. & Name & Modeling center/notes \\
\hline $1 \mathrm{a}$ & ACCESS1.0 & Commonwealth Scientific and Industrial Research \\
\hline $1 b$ & ACCESS1.3 $3^{3}$ & $\begin{array}{l}\text { Organization (CSIRO) and Bureau of } \\
\text { Meteorology (BOM), Australia }\end{array}$ \\
\hline $2 \mathrm{a}$ & BCC-CSM1.1 $1^{1,3}$ & Beijing Climate Center, China Meteorological \\
\hline $2 b$ & BCC-CSM1.1(m) ${ }^{4}$ & Administration \\
\hline 3 & BNU-ESM & $\begin{array}{l}\text { College of Global Change and Earth System Science, } \\
\text { Beijing Normal University }\end{array}$ \\
\hline 4 & CanESM2 ${ }^{3}$ & $\begin{array}{l}\text { Canadian Centre for Climate Modelling and } \\
\text { Analysis }\end{array}$ \\
\hline 5 & $\mathrm{CCSM} 4^{4}$ & National Center for Atmospheric Research \\
\hline $6 \mathrm{a}$ & CESM1 (BGC) & Community Earth System Model contributors \\
\hline $6 b$ & CESM1 (CAM5) ${ }^{2}$ & \\
\hline $6 c$ & CESM1(FASTCHEM) & \\
\hline $6 \mathrm{~d}$ & CESM1 (WACCM) ${ }^{1}$ & \\
\hline $7 \mathrm{a}$ & $\mathrm{CMCC}^{-\mathrm{CESM}}{ }^{2}$ & Centro Euro-Mediterraneo per I Cambiamenti \\
\hline $7 b$ & $\mathrm{CMCC}^{-\mathrm{CM}^{2}}$ & Climatici \\
\hline $7 \mathrm{c}$ & $\mathrm{CMCC}^{-\mathrm{CMS}^{3}}$ & \\
\hline $8 \mathrm{a}$ & CNRM-CM5 $5^{1,4}$ & Centre National de Recherches Météorologiques/ \\
\hline $8 b$ & CNRM-CM5. $2^{1}$ & $\begin{array}{l}\text { Centre Européen de Recherche et Formation } \\
\text { Avancée en Calcul Scientifique }\end{array}$ \\
\hline 9 & CSIRO-Mk3.6.0 2,4 & $\begin{array}{l}\text { Commonwealth Scientific and Industrial Research } \\
\text { Organisation in collaboration with Queensland } \\
\text { Climate Change Centre of Excellence }\end{array}$ \\
\hline 10 & FGOALS-g2 & $\begin{array}{l}\text { LASG, Institute of Atmospheric Physics, Chinese } \\
\text { Academy of Sciences, and CESS, Tsinghua } \\
\text { University }\end{array}$ \\
\hline 11 & FIO-ESM ${ }^{4}$ & The First Institute of Oceanography, SOA, China \\
\hline $12 \mathrm{a}$ & GFDL CM3 & NOAA/Geophysical Fluid Dynamics Laboratory \\
\hline $12 b$ & GFDL-ESM2G $^{2,3}$ & \\
\hline $12 \mathrm{c}$ & GFDL-ESM2M ${ }^{4}$ & \\
\hline $13 \mathrm{a}$ & GISS-E2-H ${ }^{2,4}$ & NASA Goddard Institute for Space Studies \\
\hline $13 b$ & GISS-E2-H-CC ${ }^{2}$ & \\
\hline $13 \mathrm{c}$ & GISS-E2-R ${ }^{4}$ & \\
\hline $13 \mathrm{~d}$ & GISS-E2-R-CC ${ }^{4}$ & \\
\hline $14 \mathrm{a}$ & HadCM3 & Met Office Hadley Centre (additional realizations \\
\hline $14 \mathrm{~b}$ & HadGEM2-ES & $\begin{array}{l}\text { contributed by Instituto Nacional de Pesquisas } \\
\text { Espaciais) }\end{array}$ \\
\hline 15 & INM-CM4 $4^{2}$ & Institute for Numerical Mathematics \\
\hline $16 \mathrm{a}$ & IPSL-CM5A-LR ${ }^{2,3}$ & L'Institut Pierre-Simon Laplace \\
\hline $16 b$ & IPSL-CM5A-MR 2,3 & \\
\hline $16 \mathrm{c}$ & IPSL-CM5B-LR ${ }^{1}$ & \\
\hline $17 \mathrm{a}$ & MIROC-ESM ${ }^{2,4}$ & Japan Agency for Marine-Earth Science and \\
\hline $17 \mathrm{~b}$ & MIROC-ESM-CHEM ${ }^{2}$ & $\begin{array}{l}\text { Technology, Atmosphere and Ocean Research } \\
\text { Institute (The University of Tokyo), and National } \\
\text { Institute for Environmental Studies }\end{array}$ \\
\hline $18 \mathrm{a}$ & MIROC4h ${ }^{4}$ & Atmosphere and Ocean Research Institute (The \\
\hline $18 b$ & MIROC5 $^{1}$ & $\begin{array}{l}\text { University of Tokyo), National Institute for } \\
\text { Environmental Studies, and Japan Agency for } \\
\text { Marine-Earth Science and Technology }\end{array}$ \\
\hline $19 \mathrm{a}$ & MPI-ESM-LR ${ }^{1,3}$ & Max Planck Institute for Meteorology (MPI-M) \\
\hline $19 \mathrm{~b}$ & MPI-ESM-MR ${ }^{1,3}$ & \\
\hline $19 \mathrm{c}$ & MPI-ESM-P ${ }^{1,3}$ & \\
\hline $20 \mathrm{a}$ & MRI-CGCM $3^{1,3}$ & Meteorological Research Institute \\
\hline $20 \mathrm{~b}$ & MRI-ESM1 $1^{1,3}$ & \\
\hline $21 \mathrm{a}$ & NorESM1-M & Norwegian Climate Centre \\
\hline $21 b$ & NorESM1-ME ${ }^{1}$ & \\
\hline
\end{tabular}


pressure vertical velocity at $500 \mathrm{hPa}\left(\omega_{500}\right)$, and zonal winds $(u)$, meridional winds $(v)$, and geopotential height (zg) at various levels $(850,500$, and $200 \mathrm{hPa})$. The analysis spans 50 years of the historical experiment (1950-99), a length comparable to the reanalysis used (see section 2b). Subsets of the models are used in some of the figures to demonstrate interensemble differences; these subsets are indicated in Table 1.

\section{b. Observations and reanalyses}

Models are compared with a number of observation and reanalyses datasets: sea surface temperature from Hadley Centre Sea Ice and Sea Surface Temperature dataset (HadISST; Rayner et al. 2003), vertical velocity at $500 \mathrm{hPa}$, geopotential heights, and zonal and meridional winds from ERA-Interim (Dee et al. 2011), and precipitation from Global Precipitation Climatology Project, version 2.3, Combined Precipitation Dataset (GPCP; Adler et al. 2003). Analysis using this data spans the 30-yr period 1980-2009.

\section{Methods}

The Rossby wave source $S$ (Sardeshmukh and Hoskins 1988) is calculated using

$$
S=-\nabla \cdot\left(\mathbf{v}_{\chi} \zeta\right)=-\left(\zeta \nabla \cdot \mathbf{v}_{\chi}+\mathbf{v}_{\chi} \cdot \nabla \zeta\right)
$$

where $\mathbf{v}_{\chi}$ is the divergent component of the horizontal winds and $\zeta$ is the absolute vorticity. Therefore $S$ is the sum of a rate of change of vorticity as a result of vortex stretching $\left(-\zeta \nabla \cdot \mathbf{v}_{\chi}\right)$ and as a result of vortex advection by divergent winds $\left(-\mathbf{v}_{\chi} \cdot \nabla \zeta\right) ; S$ is calculated at $200 \mathrm{hPa}$, as this is the level at which $S$ tends to peak (Sardeshmukh and Hoskins 1988; Scaife et al. 2017).

El Niño composites of the horizontal components of wave-activity flux (see derivation in Takaya and Nakamura 2001) in CMIP5 models are also calculated as follows:

$$
\begin{aligned}
& W_{1}=\frac{p}{2|\mathbf{U}|}\left[u\left(\psi_{x}^{2}-\psi^{\prime} \psi_{x x}^{\prime}\right)+v\left(\psi_{x}^{\prime} \psi_{y}^{\prime}-\psi^{\prime} \psi_{x y}^{\prime}\right)\right], \\
& W_{2}=\frac{p}{2|\mathbf{U}|}\left[u\left(\psi_{x}^{\prime} \psi_{y}^{\prime}-\psi^{\prime} \psi_{x y}^{\prime}\right)+v\left(\psi_{y}^{\prime 2}-\psi^{\prime} \psi_{y y}^{\prime}\right)\right],
\end{aligned}
$$

where $W_{1}$ and $W_{2}$ are the zonal and meridional components, respectively, of a phase-independent flux for quasigeostrophic eddies that is parallel to the local three-dimensional group velocity of Rossby waves; $p$ is pressure; $|\mathbf{U}|$ is horizontal wind speed; $u$ and $v$ are zonal and meridional winds, respectively; and $\psi^{\prime}$ is perturbation streamfunction. Zonal and meridional derivatives are indicated by $x$ and $y$ subscripts, respectively.
This flux $\mathbf{W}$ provides an idea of the direction of wave propagation.

The analysis primarily uses linear regression coefficients of seasonal anomalies onto Niño-3.4 area-averaged anomalous December-February (DJF) precipitation or temperature:

$$
Y^{\prime}=b P_{3.4}^{\prime}
$$

where $Y^{\prime}$ is DJF anomalies of some atmospheric variable, such as precipitation or geopotential height, and $P_{3.4}^{\prime}$ is DJF anomalous precipitation averaged over the Niño-3.4 region. The coefficient $b$ represents the strength of the boreal winter climate responses that are associated with ENSO-related anomalies. Atmospheric responses are regressed on DJF precipitation anomalies, not SSTAs such as is common for ENSO ocean-atmosphere feedback studies (i.e., Bellenger et al. 2014). This is because the aim of the study is to focus primarily on the atmospheric responses during ENSO. Since wave trains are primarily thought to result from changes in convection (Zhang et al. 1996) we mainly focus on the responses in relation to anomalous precipitation, rather than introduce variation resulting from model bias in the atmospheric response to ENSO SSTA.

Anomalies are calculated by removing the annual cycle. Data are detrended prior to linear fits being calculated. Averaging regions are identified that are deemed to be important for quantifying various atmospheric responses. These are introduced throughout the manuscript.

The role of the early winter mean state (DecemberJanuary) on ENSO teleconnections is examined, as opposed to the full winter season of DJF. These are the months of the atmospheric mean state with the strongest link to WNP precipitation responses and the Kuroshio anticyclone. This is also the time of year in which forcing of the Kuroshio anticyclone typically occurs (Son et al. 2014; S. Kim et al. 2017). However, mean-state relationships associated with central Pacific ENSO precipitation responses and the North Pacific cyclone are slightly weakened, compared to those using the full winter mean. Despite this all mean-state relationships discussed are significant both for DJ mean state and DJF mean state, and differences between the two are marginal (not shown in figures). The winter mean state is calculated for all years in the period, including El Niño and La Niña. Note that removal of El Niño and La Niña years from this analysis does not have a large impact on final results (not shown in figures).

Correlation analysis is carried out on the CMIP5 ensemble to examine relationships between the tropical mean state and ENSO atmospheric responses. Two 
TABLE 2. Pearson's correlation coefficients between CMIP5 area-averaged DJF precipitation (precipitation regressed onto Niño3.4-averaged precipitation anomalies $d P^{\prime} / d P_{3.4}^{\prime}$ ), CMIP5 area-averaged DJF SST responses (SST anomalies regressed onto Niño-3.4averaged SST anomalies $\left.d T^{\prime} / d T_{3.4}^{\prime}\right)$, the Kuroshio anticyclone, the North Pacific cyclone, Rossby wave sources, and metrics of the mean state during December and January. Mean1 signifies an ITCZ zonal difference of mean $\omega_{500}\left(0^{\circ}-10^{\circ} \mathrm{N}, 130^{\circ}-160^{\circ} \mathrm{E}\right.$ minus $0^{\circ}-10^{\circ} \mathrm{N}, 80^{\circ}-$ $\left.130^{\circ} \mathrm{E}\right)$. Mean 2 signifies mean $\omega_{500}$ in the central equatorial Pacific $\left(5^{\circ} \mathrm{S}-5^{\circ} \mathrm{N}, 170^{\circ} \mathrm{E}-140^{\circ} \mathrm{W}\right)$. Correlations in boldface are significant at the $95 \%$ level using the $t$ test $(N=20 ; r= \pm 0.42)$.

\begin{tabular}{|c|c|c|c|c|c|c|c|c|c|}
\hline & KAC & NPC & $\mathrm{WNP} d P^{\prime} / d P_{3.4}^{\prime}$ & $\mathrm{CP} d P^{\prime} / d T_{3.4}^{\prime}$ & $\mathrm{WP} d P^{\prime} / d P_{3.4}^{\prime}$ & RWS1 & RWS2 & $\mathrm{WP} d T^{\prime} / d T_{3.4}^{\prime}$ & Mean1 \\
\hline NPC & -0.13 & - & & & & & & & \\
\hline $\mathrm{WNP} d P^{\prime} / d P_{3.4}^{\prime}$ & -0.76 & 0.08 & - & & & & & & \\
\hline $\mathrm{CP} d P^{\prime} / d T_{3.4}^{\prime}$ & -0.33 & 0.54 & 0.25 & - & & & & & \\
\hline WP $d P^{\prime} / d P_{3.4}^{\prime}$ & 0.62 & -0.48 & -0.75 & -0.66 & - & & & & \\
\hline RWS1 & -0.78 & -0.24 & 0.86 & 0.16 & --0.58 & - & & & \\
\hline RWS2 & 0.75 & -0.52 & -0.8 & -0.62 & 0.91 & -0.64 & - & & \\
\hline $\mathrm{WP} d T^{\prime} / d T_{3.4}^{\prime}$ & -0.13 & -0.26 & 0.18 & -0.56 & 0.3 & 0.2 & 0.12 & - & \\
\hline Mean1 & -0.62 & 0.24 & 0.58 & 0.23 & -0.4 & 0.56 & -0.6 & 0.4 & - \\
\hline Mean2 & 0.22 & -0.54 & -0.22 & -0.85 & 0.61 & -0.06 & 0.47 & 0.47 & -0.19 \\
\hline
\end{tabular}

measures of correlation are calculated: the Pearson's product moment correlation and Spearman's rank correlation. Spearman's is used to account for nonlinear relationships. Both statistics are given in scatterplots and in summary Tables 2 and 3. For simplicity the text only refers to Pearson's statistics, but both are used to determine the robustness of the relationships. For significance testing of Pearson's correlations, $N$ is taken to be 20 , thus reducing the degrees of freedom. This is because coupled climate models can often share similar features and therefore may have relatively similar results (e.g., Pennell and Reichler 2011). While this cannot be completely accounted for, reducing the degrees of freedom for significance testing allows correlations to be more robustly tested.

\section{Results}

a. Biases in the Kuroshio anticyclone and North Pacific cyclone and related processes in CMIP5 models

Anomalous precipitation in the Korean Peninsula during El Niño is suggested to be a result of an anomalous anticyclone over the Kuroshio extension (Fig. 1c), located around $35^{\circ} \mathrm{N}, 150^{\circ} \mathrm{E}$, to the north of the Philippine Sea, and is visible at $500 \mathrm{hPa}$ but is less strong at lower levels (Son et al. 2014; Fig. 1b). The anticyclone is comparatively weak in DJF, as shown in Fig. 1c, since the anticyclone is stronger in early winter, then decays in January. The anticyclone is a result of anomalous Rossby waves originating from the El Niño-related negative precipitation anomalies in the WNP (Son et al. 2014). Such Rossby waves are understood to propagate northeastward, as indicated by the wave train in Figs. $1 \mathrm{~b}$ and $1 \mathrm{c}$ and the El Niño composite wave activity flux (Fig. 1d), and can impact climate in other parts of the world, such as North America.

The regions shown by green and purple boxes in Fig. 1a are used to categorize the CMIP5 models into four groups in order to examine atmospheric response biases in the CMIP5 models. These regions are chosen with reference to the study by Son et al. (2014) that investigated precipitation responses that force ENSO teleconnection patterns, as well as examination of the CMIP5 ENSO precipitation response multimodel variance, in order to capture the regions where precipitation

TABLE 3. As in Table 2, but for Spearman's correlation coefficients. Correlations in boldface are when the Pearson's correlation was $95 \%$ significant using the $t$ test $(N=20 ; r= \pm 0.42)$.

\begin{tabular}{|c|c|c|c|c|c|c|c|c|c|}
\hline & $\mathrm{KAC}$ & NPC & $\mathrm{WNP} d P^{\prime} / d P_{3.4}^{\prime}$ & $\mathrm{CP} d P^{\prime} / d T_{3.4}^{\prime}$ & $\mathrm{WP} d P^{\prime} / d P_{3.4}^{\prime}$ & RWS1 & RWS2 & $\mathrm{WP} d T^{\prime} / d T_{3.4}^{\prime}$ & Mean1 \\
\hline NPC & 0.08 & - & & & & & & & \\
\hline $\mathrm{WNP} d P^{\prime} / d P_{3.4}^{\prime}$ & -0.41 & -0.08 & - & & & & & & \\
\hline $\mathrm{CP} d P^{\prime} / d T_{3.4}^{\prime}{ }^{3.4}$ & -0.19 & 0.47 & -0.11 & - & & & & & \\
\hline $\mathrm{WP} d P^{\prime} / d P_{3.4}^{\prime}$ & 0.07 & -0.61 & 0.04 & -0.8 & - & & & & \\
\hline RWS1 & -0.66 & -0.43 & 0.68 & -0.09 & 0.2 & - & & & \\
\hline RWS2 & 0.55 & -0.48 & -0.32 & -0.6 & 0.61 & -0.26 & - & & \\
\hline $\mathrm{WP} d T^{\prime} / d T_{3.4}^{\prime}$ & -0.28 & -0.28 & 0.47 & -0.6 & 0.58 & 0.47 & 0.15 & - & \\
\hline Mean1 & -0.62 & 0.20 & 0.52 & 0.15 & -0.16 & 0.53 & -0.56 & 0.45 & - \\
\hline Mean2 & 0.12 & -0.52 & 0.01 & -0.80 & 0.7 & 0.11 & 0.52 & 0.47 & -0.13 \\
\hline
\end{tabular}



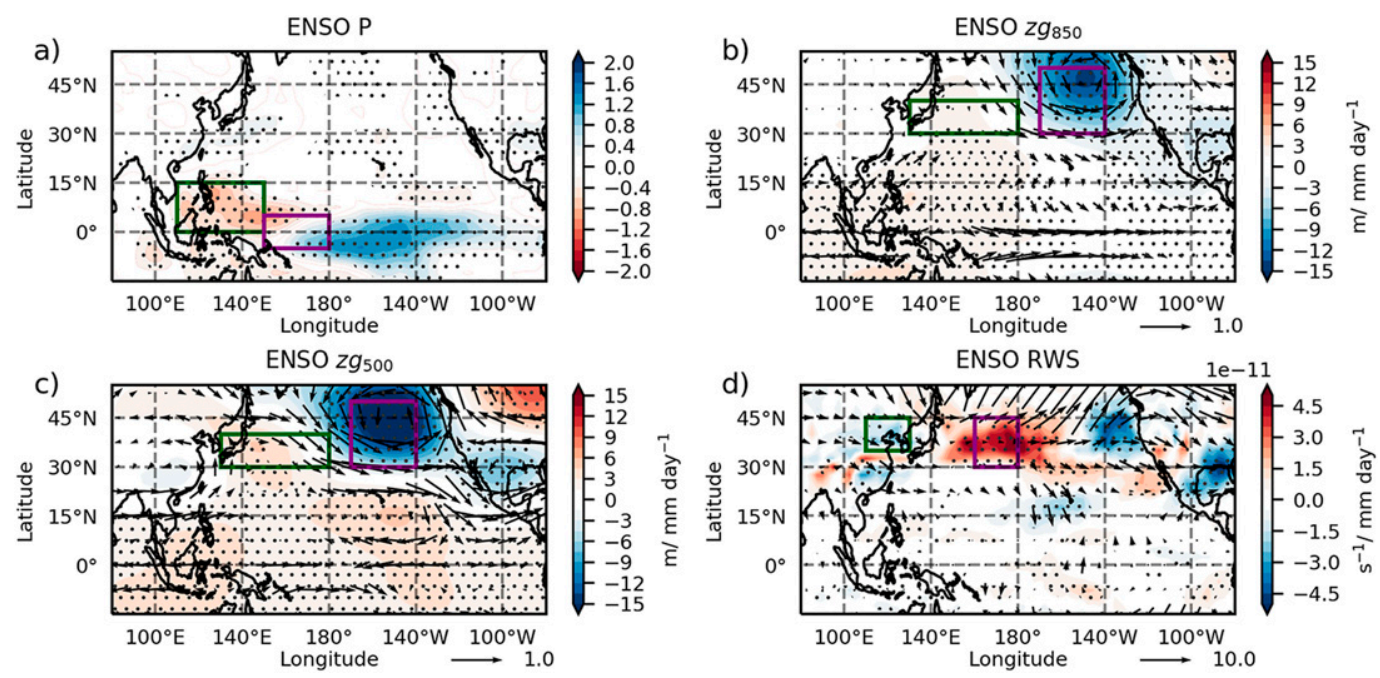

FIG. 1. (a) GPCP winter-ENSO-related precipitation (regression of gridded DJF precipitation anomalies on Niño-3.4 area-averaged DJF precipitation anomalies) for 1980-2009. (b) As in (a), but for ERA-Interim geopotential height at $850 \mathrm{hPa}$. (c) As in (a), but for ERA-Interim geopotential height at $500 \mathrm{hPa}$. (d) As in (a), but for Rossby wave source at $200 \mathrm{hPa}$ calculated using ERA-Interim. Stippling indicates regression significant at $95 \%$ level using the $t$ test. Arrows in (b) and (c) indicate the wind vectors $\left(\mathrm{m} \mathrm{s}^{-1}\right)$ at those pressure levels; arrows in (d) indicate El Niño composite wave activity flux $\left(\mathrm{m}^{2} \mathrm{~s}^{-2}\right)$. Boxed regions represent precipitation response area-averaged regions: (a) WNP (green) and WP (purple), (b),(c) Kuroshio anticyclone (green) and North Pacific cyclone (purple) area-averaged regions, and (d) RWS1 (green) and RWS2 (purple) area-averaging regions.

responses vary most in models (not shown in figures). The first group (hereafter WNPstrong) contains 12 models with the strongest negative western North Pacific (WNP; west boxed region in Fig. 1a) precipitation response during El Niño events (Fig. 2a). The second group (WNPweak) contains 12 models with weak negative, or positive, precipitation responses in this region (Fig. 2c). The final two groups are based on the west equatorial Pacific precipitation (referred to hereafter as WP; the purple-boxed region in Fig. 1a) regressed on the Niño3.4 ENSO precipitation anomaly and consists of 12 models with a weak positive response in this region (WPweak; Fig. 2b), and 12 models with the largest precipitation response in this region (WPstrong; Fig. 2d). The multimodel averages of these groups are used to gain a simple overview of variations in strength and spatial distribution of atmospheric responses to ENSO events. See Table 1 for further details of the models in each group. It should be noted that there is some overlap between the groups, but no two groups have all models in common. The most similar groups are WNPstrong and WPstrong that have six models in common (all MPI and MRI models and BCC-CSM1.1). The remaining groups have at most three models in common.

Figure 2 indicates that WNPstrong (Fig. 2a) and WPstrong (Fig. 2d) models have a similar spatial distribution of anomalous precipitation during ENSO events. In comparison to observations, the positive precipitation response along the equator is shifted to the west by approximately $20^{\circ}$ longitude, and is larger in magnitude; the strength of the response in the central equatorial Pacific is comparatively small. There are also relatively strong negative precipitation anomalies in the east, to the north of the equator, centered at approximately $10^{\circ} \mathrm{N}, 130^{\circ} \mathrm{W}$. One model of WPstrong (seven of WNPstrong) has a correlation between the modeled precipitation response spatial pattern and the observed spatial pattern greater than 0.6.

Means of the ENSO precipitation response in WNPweak and WPweak models (Figs. 2b,c) are somewhat different to one another. The WNPweak precipitation response shows a similar pattern to the WNPstrong and WPstrong precipitation responses, but with a reduced magnitude. Notably, the positive precipitation anomaly along the equator is shifted westward, by approximately $30^{\circ}$ longitude compared to observations (Fig. 1a), extending into the green-boxed region. The magnitude of the WNPweak ensemble mean is weak relative to observations. WPweak models have an anomalous precipitation spatial distribution much more similar to observations than any of the other model groups (all of the 12 models have a spatial correlation with the observed pattern greater than 0.6), albeit at a weaker magnitude (Fig. 2b). 

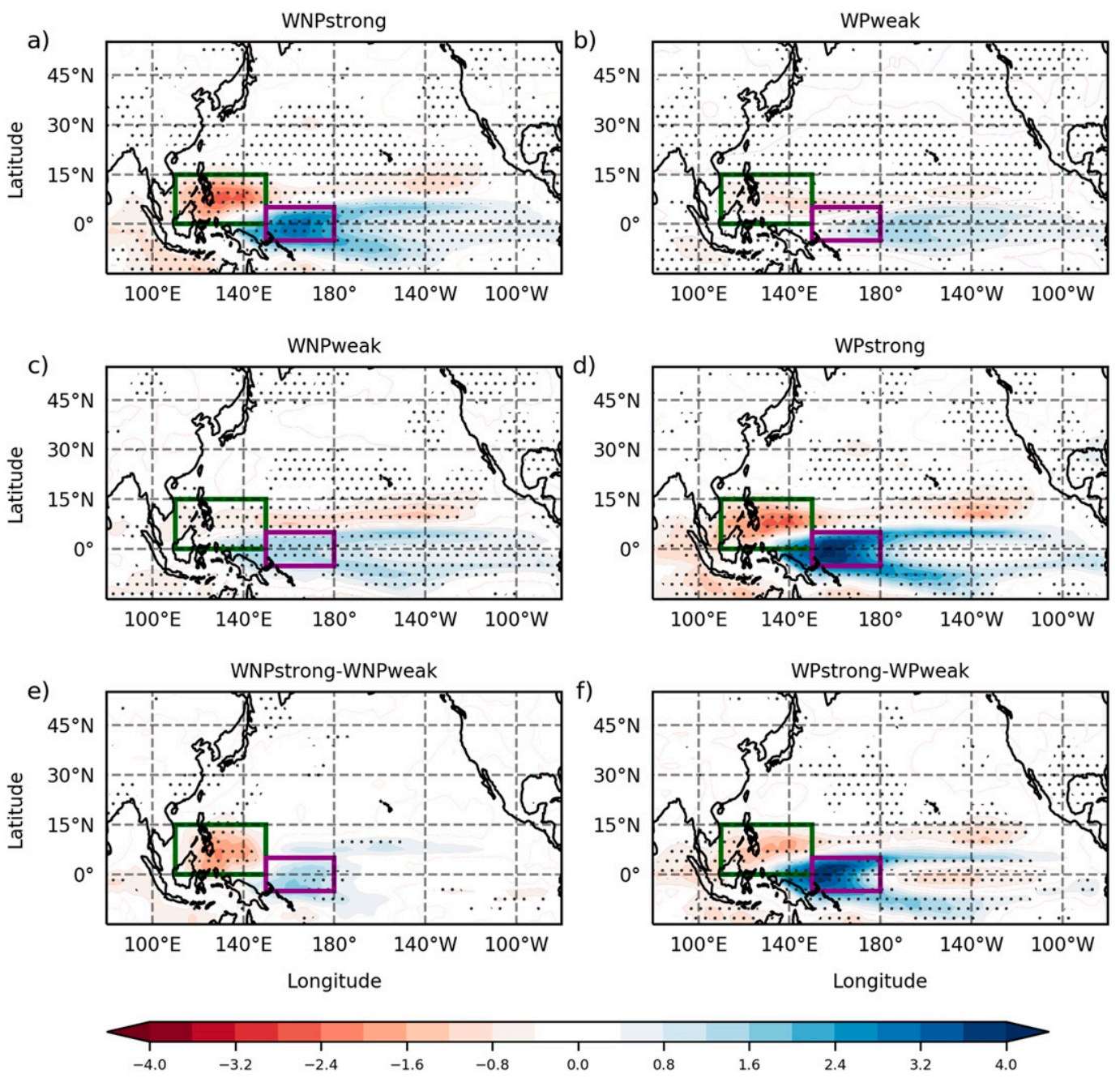

FIG. 2. (a) CMIP5 mean of winter-ENSO-related precipitation response (regression of gridded DJF precipitation anomalies on Niño-3.4 area-averaged DJF precipitation anomalies) for 12 models with the largest negative area-averaged ENSO-related WNP precipitation response (WNPstrong). (b) As in (a), but for 12 models with the smallest positive, or that have negative, WP ENSO-related precipitation response (WPweak). (c) As in (a), but for 12 models with the smallest negative WNP ENSO-related precipitation response (WNPweak). (d) As in (a), but for 12 models with the largest positive WP ENSO-related precipitation response (WPstrong). (e) The difference between (a) and (c). (f) The difference between (b) and (d). Boxed regions represent precipitation response area-averaging regions: WNP (green) and WP (purple). Stippling in (a)-(d) indicates regions where $80 \%$ of models ( 10 or more) agree with the sign of the model mean. Stippling in (e) and (f) indicates where the difference between the two subensemble means is significant at the $95 \%$ level using the two-tailed Student's $t$ test.

Differences between the "strong" and "weak" precipitation response groups are shown in Figs. 2e and 2f. Differences between the four group means show that the WNPstrong and WPstrong means are significantly different from the respective WNPweak and WPweak means in the relevant regions. Models have biases in precipitation responses that can be a result of bias in the spatial distribution of the atmospheric circulation responses, a bias in magnitude, or a combination of both. Subsequent figures examine the biases in corresponding Rossby wave sources and geopotential height patterns during events.

The ENSO wave source responses and El Niño composite of wave activity fluxes [Eqs. (2) and (3)] are shown in Fig. 3. Wave activity fluxes of all four groups show northeastward propagation of waves from the source regions toward North America, as observed in Fig. 1d. However, biases may be introduced by the forcing of waves. The model groups have varying magnitudes of wave source, but less variation in source 

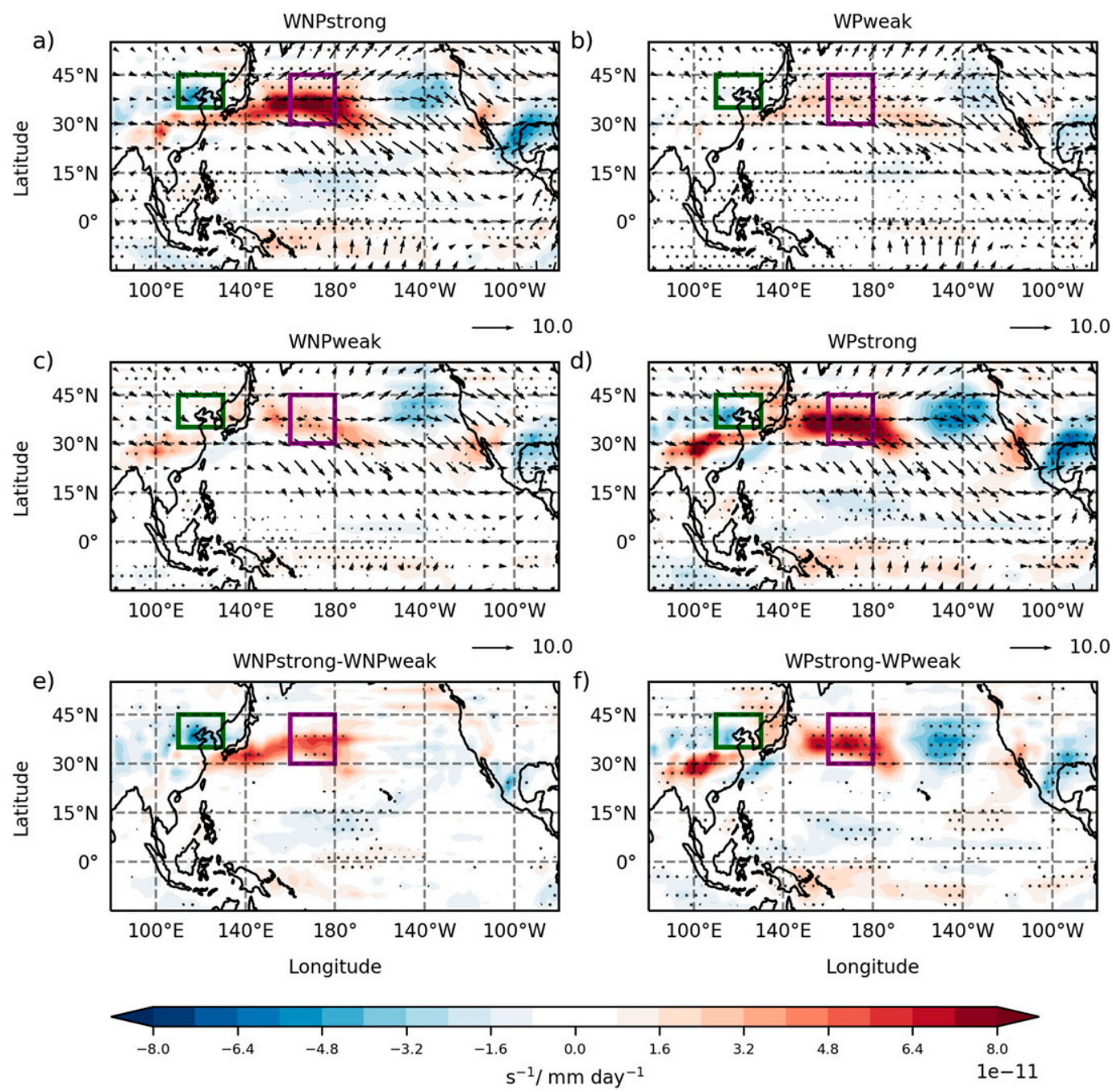

FIG. 3. As in Fig. 2, but for the winter-ENSO-related Rossby wave source response (regression of gridded DJF Rossby wave source anomalies on Niño-3.4 area-averaged DJF precipitation anomalies).

spatial distribution. Scaife et al. (2017) similarly found, in a forecast model, that the spatial pattern of wave sources was relatively unchanged regardless of the location at which precipitation forcing was applied. Differences between the model groups are evident in the negative source region over East Asia. WNPweak and WPweak models fail to generate the negative source over North China (Figs. 3b,c), which may result in a failure to generate the Kuroshio anticyclone (KAC) in those models. However, both group means still have a positive wave source across the North Pacific, though this is much weaker (Figs. 3b,c). This suggests that these models may still replicate the North Pacific cyclone (NPC) to some extent. WNPstrong and WPstrong model means have strong Rossby wave sources in a similar spatial distribution to those observed (Figs. 3a,d). Those models are therefore more likely to successfully replicate the KAC and NPC, assuming that bias lies mainly with the source of the Rossby waves that generate the ENSO teleconnection.

Differences between the WNPstrong and WNPweak groups show that the negative source over China in WNPstrong is significantly reduced in the WNPweak model mean, as is the positive North Pacific wave source (Fig. 3e). The difference between WPstrong and WPweak shows the reduction in the negative wave source over China is not significant, but there is a significant reduction in the positive North Pacific wave source (Fig. 3f). Boxed regions in Fig. 3 are defined to highlight the location of the relevant sources (referred to as RWS1 and RWS2 for green and purple regions, respectively) that are present in observations (Fig. 1d) and that vary between the model subensembles (Figs. 3e,f). 

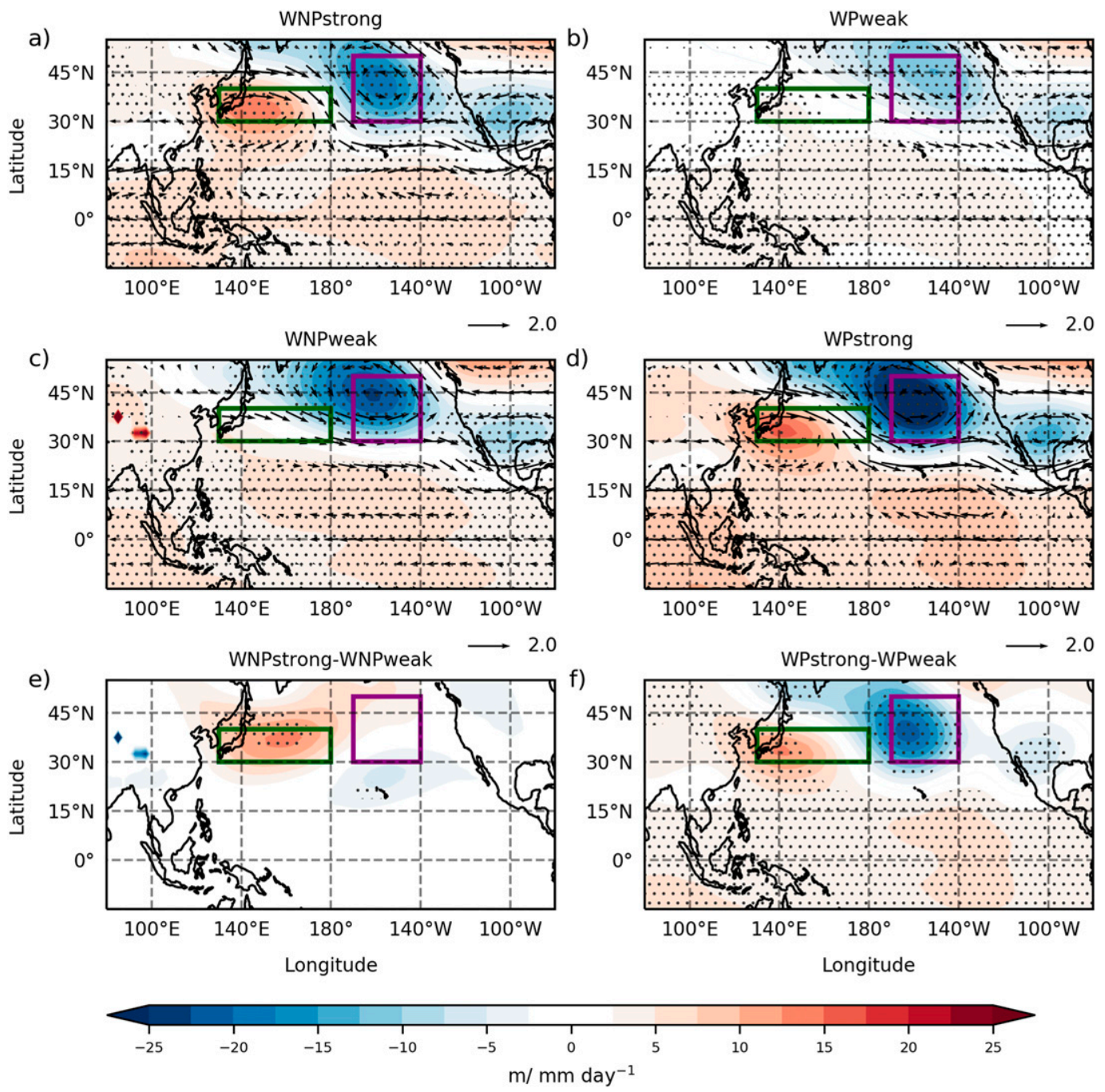

FIG. 4. As in Fig. 2, but for the winter-ENSO-related 500-hPa geopotential height response (regression of gridded DJF geopotential height anomalies on Niño-3.4 area-averaged DJF precipitation anomalies.

The ENSO geopotential height at $500 \mathrm{hPa}$ is also examined (Fig. 4). WNPstrong and WPstrong model means are indeed found to have a KAC and a NPC during El Niño (Figs. 4a,d), though the magnitudes are larger than observed. This may be a result of the relatively strong forcing of the Northern Hemisphere Rossby waves (Figs. 2 and 3). For WNPweak and WPweak the KAC is less evident and the NPC tends to dominate the response. This is particularly the case in WNPweak models, where the model mean shows the NPC extends farther west by approximately $20^{\circ}$ compared with the observed NPC (Fig. 4c). Note that the NPC in WNPweak ensemble mean appears larger in magnitude than that in the WNPstrong ensemble mean, despite a weaker positive source. However, the difference between the two subensembles shows this is not a significant difference (Fig. 4e). For the WPweak model mean, there is a relatively weak NPC that is confined to the east Pacific as observed, though still a weak or nonexistent KAC (Fig. 4b).

Examining the differences in the WNPstrong and WPstrong groups to the respective weak groups shows that in models with significantly different WNP precipitation responses there is a significantly reduced KAC (Fig. 4e). In models with significantly different WP precipitation responses there is also a significantly different strength in the NPC (Fig. 4f). Boxed regions in Fig. 4 are defined to capture the interensemble variation in the KAC (green box) and NPC (purple box) in subsequent analysis.

It is known that SSTA bias is also linked to the precipitation response biases (i.e., Ham and Kug 2015) and 
ENSO teleconnections (i.e., Coats et al. 2013). Ham and Kug (2015) find that models with ENSO SSTAs extending farther west also have a westward-shifted precipitation response. Tables 2 and 3 shows that indeed the strength of the SSTA response in the WP region is significantly linked to the CP and WP precipitation responses. Similarly, the difference in the model-mean SSTA responses between the WPstrong and WPweak groups show significantly increased SSTAs in the WP region in the WPstrong models (not shown in figures). However, the SSTA interensemble variation shows no strong linkage to the subsequent teleconnection pattern as shown by the correlations in Tables 2 and 3, and so is not a primary focus of this study, but undoubtedly contributes to biases in the precipitation response, indicating an area of focus for improvement of future model ENSO precipitation response.

These results show that biases in the teleconnection patterns are linked to biases in the initial precipitation forcing of the teleconnection patterns, as well as errors in corresponding Rossby wave sources. It is possible that biases in the mean state modulate the responses that drive the teleconnection, as they are known to do with similar atmospheric responses that drive, and are associated with, ENSO events (Kim et al. 2013; Ham and Kug 2015; Ferrett et al. 2017, 2018). This is examined in the following section.

\section{b. The role of the atmospheric mean state in ENSO atmospheric processes}

The early winter (DJ) mean atmospheric conditions in the tropical Pacific are characterized by regions of precipitation in the west equatorial Pacific (Fig. 5a), along a band slightly to the north of the equator, the intertropical convergence zone (ITCZ), and in a region to the south of the equator, the South Pacific convergence zone (SPCZ). These regions also have strong atmospheric ascent, shown by negative $500-\mathrm{hPa}$ vertical velocity $\omega_{500}$ in Fig. 5b. There is atmospheric descent and little precipitation farther north. Farther to the east along the equator, over the cold tongue, conditions are relatively dry in the mean state and there is atmospheric descent (the Walker circulation). A further band of precipitation and atmospheric ascent is seen in the North Pacific around $35^{\circ}-45^{\circ} \mathrm{N}$, that is stronger in the east. Farther west over the Indian Ocean most precipitation and ascent is located closer to the equator than in the west Pacific and peaks slightly to the south of the equator.

Figures 6 and 7 demonstrate the winter (DJ) meanstate precipitation and pressure vertical velocity biases associated with varying precipitation responses during El Niño of the four groups shown in Figs. 2-4. WNPstrong

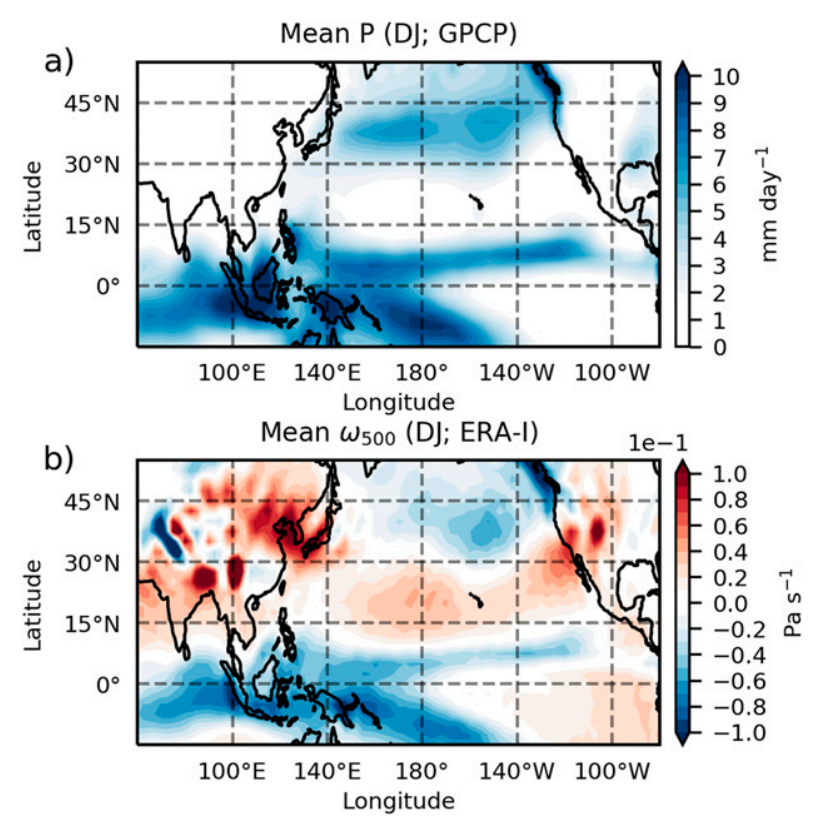

FIG. 5. (a) GPCP winter (DJ) mean precipitation for 1980-2009. (b) As in (a), but for ERA-Interim vertical velocity at $500 \mathrm{hPa}\left(\omega_{500}\right)$.

and WPstrong model means have a more pronounced zonal gradient in mean precipitation and $\omega_{500}$ over the WNP and north Indian Ocean (NIO). There is reduced precipitation and atmospheric ascent over the NIO, and stronger precipitation and ascent over the west region of the Pacific ITCZ (Figs. 6a,d and 7a,d). These differences are only significant between the WNP group means (Fig. 6e). This suggests there are zonal biases in atmospheric circulation patterns in the tropical Pacific for these models, with a tendency to have a larger amount of precipitation over the western North Pacific and more atmospheric ascent there that may be indicative of more unstable atmospheric conditions, relative to the north Indian Ocean (WNPstrong).

There are also evident equatorial Pacific biases, with reduced precipitation and ascent in the central equatorial Pacific, and enhanced precipitation and ascent farther west, demonstrating a westward shift in the ascending branch of the Walker circulation compared with observations. This shift in the Walker circulation means there is reduced atmospheric ascent in the central Pacific and the precipitation response there is suppressed, while the precipitation response farther west is enhanced, in agreement with previous studies (i.e., Ham and Kug 2015). This bias is particularly strong in the WPstrong group of models (Figs. 6d and 7d) and the difference between the WPstrong and WPweak means show significantly less mean precipitation and atmospheric descent in the equatorial Pacific for the WPstrong model mean, compared with the WPweak group (Figs. 6f and 7f). 

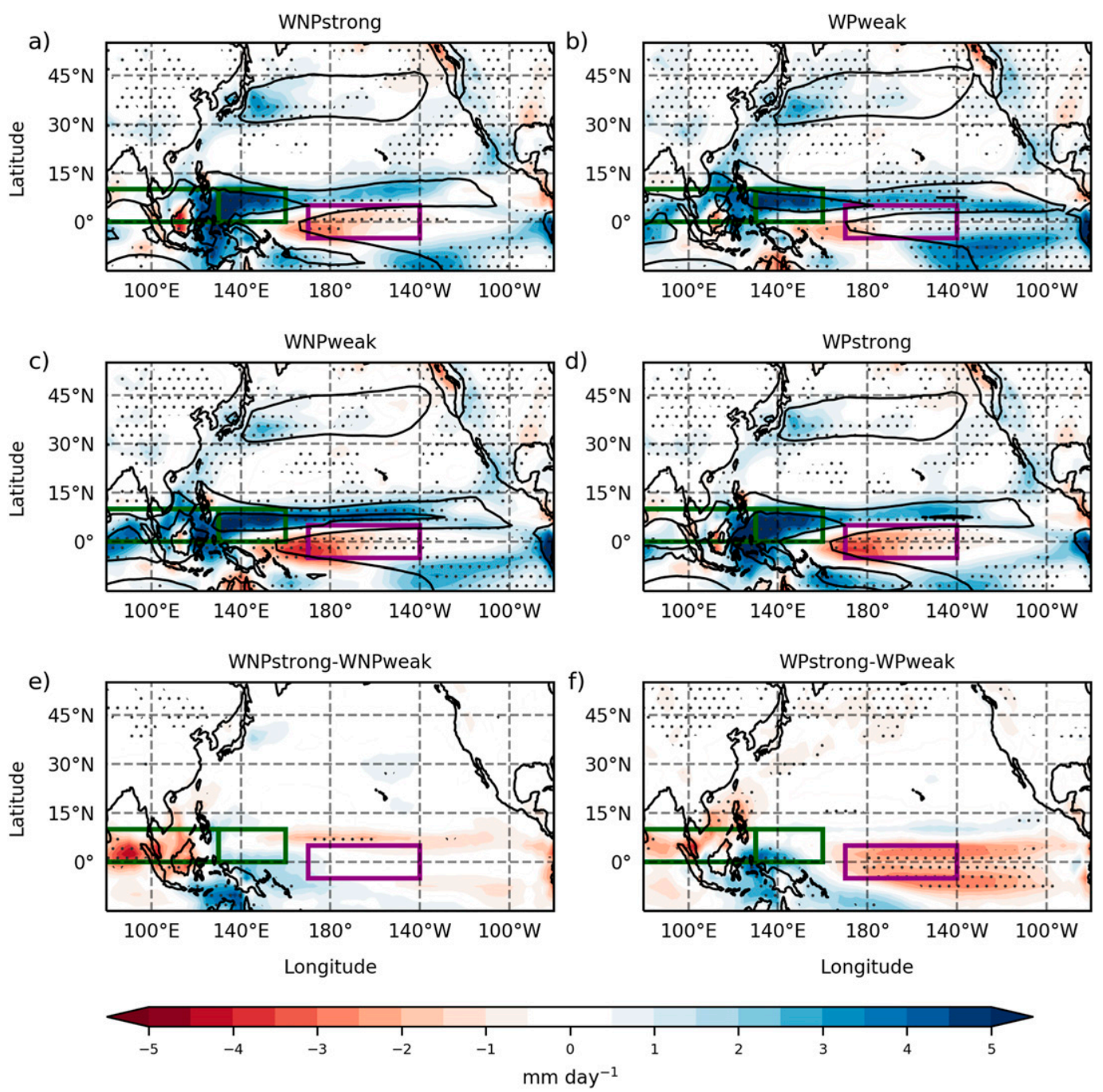

FIG. 6. (a) Subensemble bias of winter (DJ) mean precipitation (subensemble mean minus GPCP; shading) and subensemble mean of DJ precipitation (line countours) for WNPstrong. (b) As in (a), but for WPweak. (c) As in (a), but for WNPweak. (d) As in (a), but for WPstrong. (e) The difference between (a) and (c). (f) The difference between (b) and (d). Boxed regions represent mean precipitation area-averaging regions: the northwest Pacific zonal difference (Mean1; green) and the central Pacific (Mean2; purple). Stippling in (a)-(d) indicates regions where $80 \%$ of models (10 or more) agree with the sign of the model mean. Stippling in (e) and (f) indicates where the difference between the two subensemble means is significant at $95 \%$ level using the two-tailed Student's $t$ test. Line contours are at $5 \mathrm{~mm} \mathrm{day}^{-1}$ intervals.

The boxed regions in Figs. 6 and 7 can be used to obtain interensemble relationships between the mean state and ENSO-related atmospheric responses. It is found that a significant (at the $99 \%$ level using a $t$ test) relationship exists between the WNP precipitation response and the northwest Pacific zonal difference (east minus west; see the green boxed regions in the west in Fig. 6) of mean $\omega_{500}$ (Fig. 8a, $r=0.58$ ). This zonal difference of mean $\omega_{500}$ is labeled "Mean1" in Table 2, and is a measure of the zonal variation of atmospheric circulation in the west tropical Pacific. A more negative value of Mean1 indicates stronger atmospheric ascent over the ITCZ than the NIO, and is linked to a stronger negative WNP precipitation response to an ENSO SSTA (Fig. 8a). This mean-state metric can also be linked to a stronger anticyclone over the Kuroshio region (Fig. 8b), perhaps due to the stronger WNP precipitation response in those models (see correlations in Table 2). Models with a more positive value for Mean1 even have cyclonic anomalies in the Kuroshio region during El Niño, as also shown in Fig. 4c. 

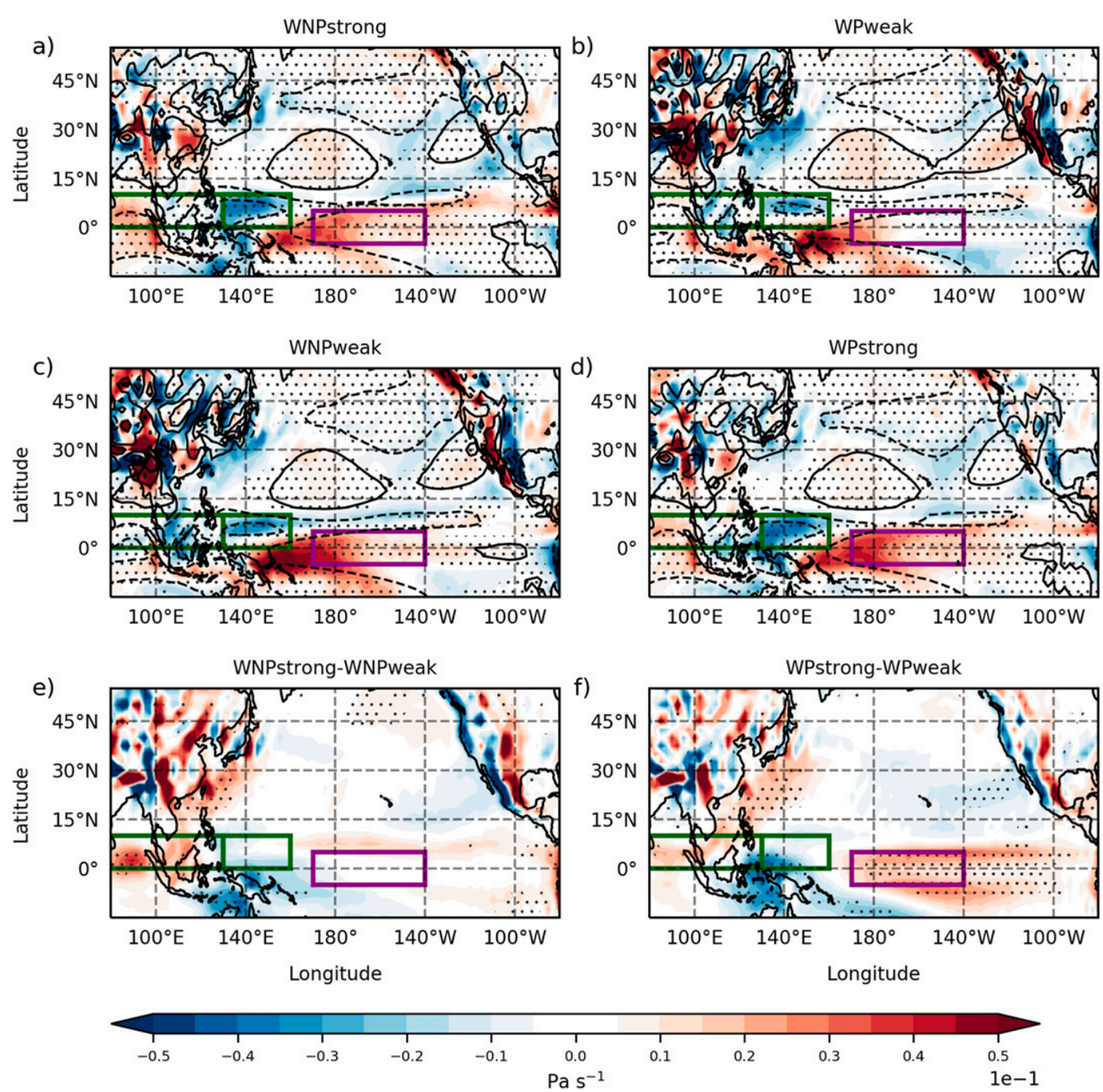

FIG. 7. As in Fig. 2, but for winter (DJ) mean $\omega_{500}$ bias (subensemble mean minus ERA-Interim) at $500 \mathrm{hPa}$. Line contours are at $0.05 \mathrm{~Pa} \mathrm{~s}^{-1}$ intervals beginning at $-0.075 \mathrm{~Pa} \mathrm{~s}^{-1}$.

Examining the central Pacific precipitation response, it is found that there is a link (Fig. 8c; $r=-0.85$ ) with central Pacific mean atmospheric conditions, labeled Mean2 in Table 2, which represents the equatorial Walker circulation bias. More atmospheric descent $\left(\omega_{500}>0\right)$ in the central Pacific is linked to a suppressed CP precipitation response to ENSO SSTAs (regression of Niño-3.4 DJF precipitation anomalies on DJF Niño3.4 SSTAs-Fig. 8c). Ferrett et al. (2018) showed how equatorial Pacific mean-state conditions, such as less mean precipitation and strong atmospheric descent, can be linked to biases in the atmospheric responses during El Niño. Namely, these mean conditions are linked to a westward shifted Walker circulation and the presence of low cloud in the east equatorial Pacific, not found in observations. The low clouds are then broken up during
El Niño, as opposed to the convection and eastward shift of the ascending branch of the Walker circulation that occurs in observations, explaining the weak precipitation response in these models.

The CP precipitation response has a negative relationship with the WP precipitation response $(r=-0.66$; Table 2) suggesting zonal differences in equatorial precipitation anomalies are linked. Models with more atmospheric descent in the central Pacific have ENSO precipitation responses located farther to the west. As such, the WP precipitation response is most strongly linked to the CP mean state (Fig. 8e). Furthermore, the strength of the NPC is also significantly linked to the CP mean state (Fig. 8f). These relationships indicate that various aspects of the tropical Pacific mean state have a linkage to the ENSO precipitation responses known to 

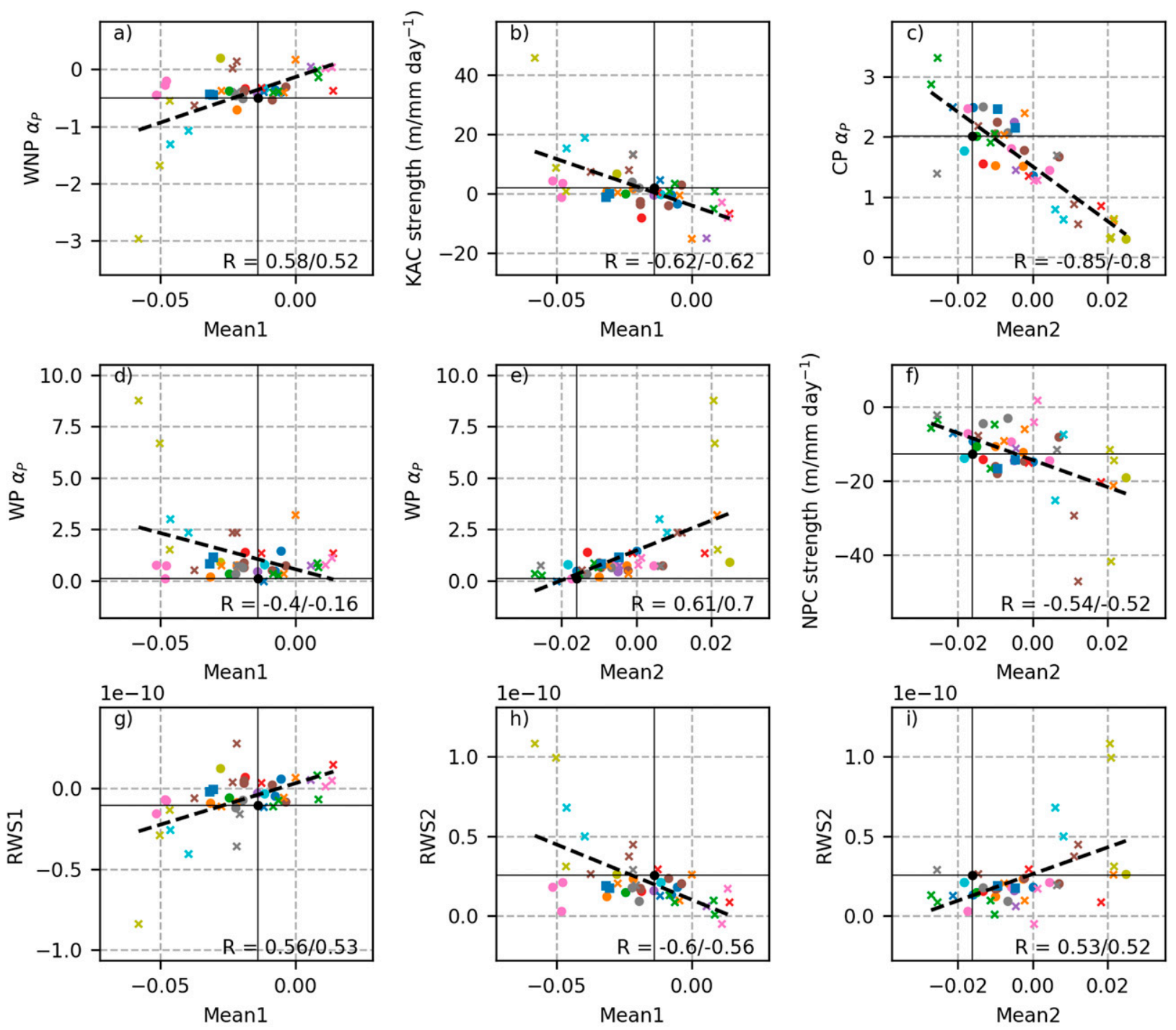

\begin{tabular}{|c|c|c|c|c|c|c|c|c|c|c|c|c|c|c|c|c|c|c|c|c|c|}
\hline & 0 & ○ & 2 & ○ & 4 & ○ & 6 & ○ & 8 & 0 & 10 & $x$ & 12 & $x$ & 14 & $x$ & 16 & $x$ & 18 & $x$ & 20 \\
\hline 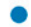 & 1 & - & 3 & ○ & 5 & ○ & 7 & ○ & 9 & $x$ & 11 & $x$ & 13 & $x$ & 15 & $x$ & 17 & $x$ & 19 & 口 & 21 \\
\hline
\end{tabular}

FIG. 8. Relationships between indices of ENSO teleconnections and mean-state biases. (a) ENSO WNP precipitation response plotted against mean DJ zonal difference in $\omega_{500}$ between NIO and WNP (Mean1). (b) ENSO Kuroshio anticyclone strength plotted against Mean1. (c) ENSO CP precipitation response plotted against mean DJ central Pacific $\omega_{500}$ (Mean2). (d) ENSO WP precipitation response plotted against Mean1. (e) ENSO WP precipitation response plotted against Mean2. (f) ENSO North Pacific cyclone strength plotted against Mean2. (f) ENSO North Pacific cyclone strength plotted against Mean2. (g) Rossby wave source in region RWS1 plotted against Mean1. (h) Rossby wave source in region RWS2 plotted against Mean1. (i) RWS2 plotted against Mean2. Dashed lines show the best-fit line. Pearson's and Spearman's correlation coefficients are shown in each panel. The numbers listed in the legend correspond to the models listed in Table 1.

force the Northern Hemisphere ENSO teleconnection pattern, and the strength of this pattern.

The North Pacific Rossby wave sources identified previously are also examined for links to the tropical Pacific mean state. RWS1 is only significantly linked to
Mean1 (Fig. 8g), whereas RWS2 can be linked to both mean-state biases in the WNP and CP (Figs. 8h,i). This may be indicative of the following relationship: tropical mean-state bias is linked to precipitation forcing bias, possibly resulting in wave source bias and subsequent 
ENSO teleconnection bias. However, caution must be exercised when suggesting a directional relationship since the Rossby wave sources may be biased as a result of the bias in the Northern Hemisphere atmospheric circulation response during ENSO, rather than vice versa. We note that the mean zonal difference in $\omega_{500}$ over the WNP and NIO is also linked to RWS2, which may suggest that atmospheric biases originating farther west are linked to this wave source bias, as opposed to only the $\mathrm{CP}$ precipitation response bias.

Here it is shown that the mean state can be linked to El Niño precipitation responses, which extend to the strength of the anomalous Kuroshio anticyclone and the North Pacific cyclone. The following section examines the link between precipitation forcing and teleconnection patterns, including Rossby wave sources, in CMIP5 models.

\section{c. The relation between ENSO-related precipitation and Northern Hemisphere teleconnection patterns}

Using the area-averaging regions outlined in Figs. 2-4 it is possible to examine interensemble relationships between El Niño precipitation forcing, Rossby wave sources, and anomalous geopotential height for all models in the CMIP5 ensemble (Fig. 9). It is shown that there is a significant relationship (at the 99\% level using a $t$ test) between the KAC and the wave source over East Asia (RWS1; $r=-0.78$ ). This suggests that bias in the forcing of the Northern Hemisphere Rossby waves is linked to the variation in the strength of the modeled teleconnection pattern.

The link between the central North Pacific wave source (RWS2) and the NPC response (Fig. 9b) is slightly weaker $(r=-0.52)$. While there is a tendency for a larger Rossby wave source in the RWS2 region to be linked to a stronger NPC (as also demonstrated by Figs. 3 and 4), it is difficult here to propose a simple relationship between RWS2 and NPC. It is possible that the generation of waves in the RWS1 region in many of the models that then propagate across the North Pacific may contribute to the NPC. However, the correlation between RWS1 and the NPC strength is relatively weak (Table 2; $r=-0.24$ ), suggesting this does not have a strong influence in all the models. It may be suspected that a strong Rossby wave source in the west Pacific will result in both a strong KAC and a strong NPC due to this wave propagation. These results suggest that this is not necessarily the case. This is also reinforced by the insignificant relationships between the KAC and NPC, as well as the lack of a relationship between the WP precipitation forcing and the WNP precipitation forcing (Table 3). There is nonetheless a link between the ENSO teleconnection pattern and modeled Rossby wave sources, particularly in the west Pacific, of particular importance to East Asia.

The relationship between Rossby wave sources and tropical Pacific ENSO precipitation responses is also examined. It is found that there is a relatively strong significant link between RWS1 and the WNP precipitation response (Fig. 9c, $r=0.86$ ). For RWS2 there is a significant link to the WP precipitation response (Fig. 9d, $r=0.91$ ). However, it is hard to establish a cause and effect relationship for the central Pacific RWS and teleconnection patterns here. Therefore, further targeted modeling studies would need to be carried out. Nonetheless, previous study by Son et al. (2014) has established a direct link between precipitation forcings and KAC and NPC atmospheric responses, supporting findings here.

Some outliers in Fig. 9 are evident, such as models 19 (yellow cross) and 20 (teal cross), and may influence the relationships strongly. Removing these models from the analysis does indeed slightly weaken the relationships, particularly that shown in Fig. 9a between the KAC and RWS1. Nonetheless, there is still a Spearman's rank correlation of -0.55 between the two, despite a reduced Pearson's product moment correlation.

Results here identify linkages between the modeled tropical Pacific forcings and resulting ENSO teleconnection patterns. Importantly, while there is evidence of interaction between responses in both regions, the strength of the anticyclone and cyclone can have independent biases; a bias in one does not always mean a bias in the other. KAC and NPC are not significantly linked (Tables 2 and 3). Therefore, it is important to consider both western and central Pacific biases in order to capture an accurate teleconnection pattern.

\section{Summary and conclusions}

Relationships between the tropical Pacific atmospheric mean state in coupled climate models and winter atmospheric responses during El Niño have been examined. There exist significant relationships between the equatorial Pacific precipitation response during El Niño and the bias in mean-state equatorial Pacific climate, related to Walker circulation spatial bias (Figs. 9c,d). This relationship has been noted in previous study (i.e., Ham and Kug 2015). This study additionally highlights a relationship between the bias in the western North Pacific negative precipitation response during El Niño and the zonal extension of the intertropical convergence zone (ITCZ) in the west Pacific and tropical Indian Ocean. Some models have an ITCZ that is too strong over the Indian Ocean, in comparison to the observed band of precipitation and atmospheric ascent 

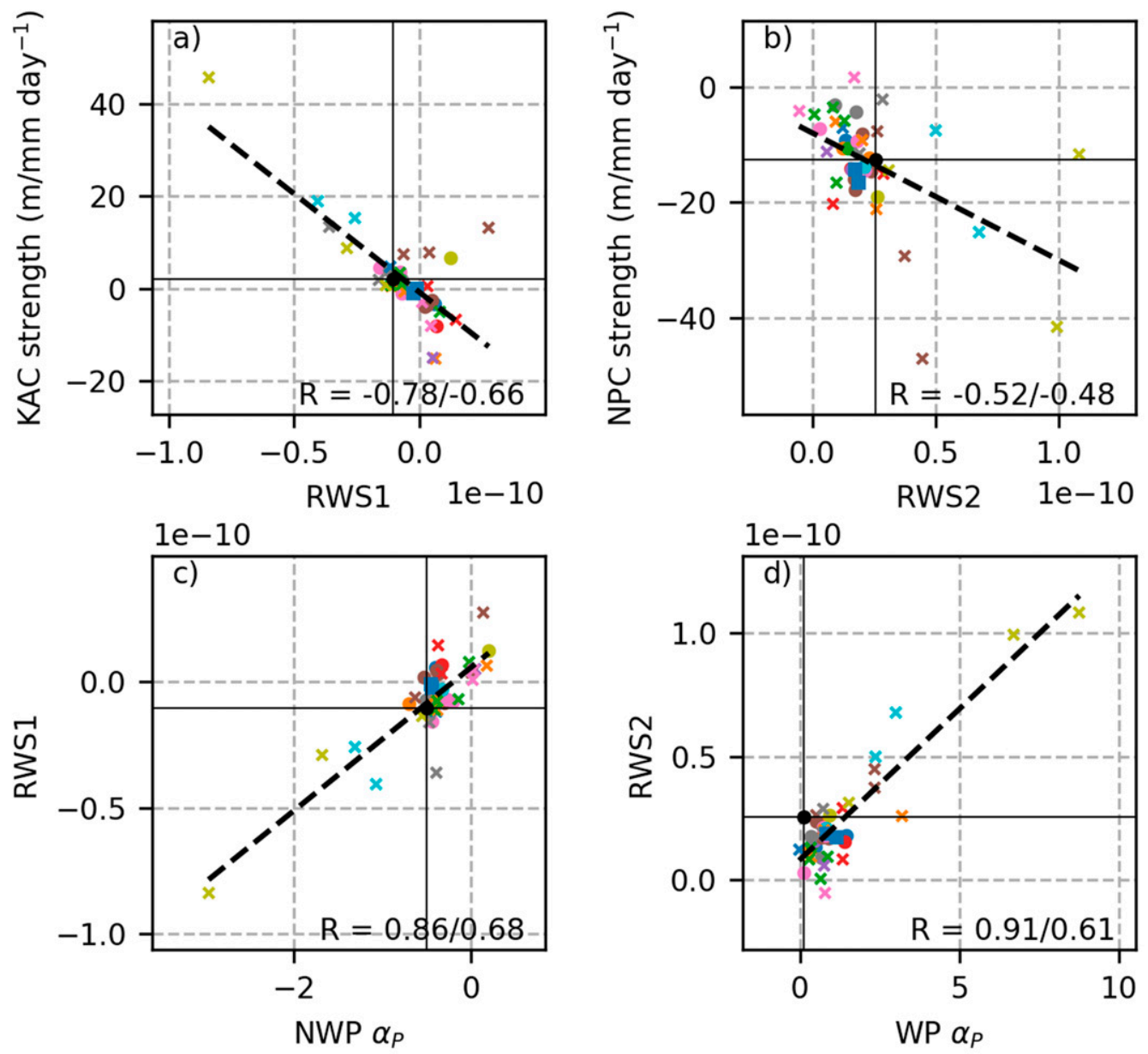

- $0 \bullet 2 \bullet 4 \bullet 6 \bullet 8 \bullet 10 \times 12 \times 14 \times 16 \times 18 \times 19 \times$

- $1 \bullet 3 \bullet 5 \bullet 7 \bullet 9 \times 11 \times 13 \times 15 \times 17 \times 19 \quad \square \quad 21$

FIG. 9. (a) CMIP5 ENSO Kuroshio anticyclone strength plotted against ENSO Rossby wave source (RWS) in region RWS1. (b) CMIP5 ENSO North Pacific cyclone strength plotted against ENSO RWS in region RWS2. (c) ENSO RWS in region RWS1 plotted against ENSO NWP precipitation response. (d) ENSO RWS in region RWS1 plotted against ENSO WP precipitation response. Dashed lines show the best-fit line. Pearson's and Spearman's correlation coefficients are shown in each panel. The numbers listed in the legend correspond to the models listed in Table 1.

spanning the Indian Ocean and the Pacific north of the equator. This bias can be linked to a weaker negative western North Pacific precipitation response during El Niño. The inverse is also true such that models with an overly strong ITCZ in the western North Pacific have a tendency for a very strong negative precipitation response (Fig. 9a). This can also enhance precipitation responses along the equator during El Niño (Table 2).

Tropical Pacific precipitation responses during El Niño have been previously shown to drive northeastwardpropagating Rossby waves that cause the teleconnection patterns in the Northern Hemisphere (i.e., Son et al. 2014; Scaife et al. 2017). Here it is shown that the influence of the mean state on El Niño precipitation responses has further impacts, such that mean-state biases are also linked to bias in Rossby wave sources and corresponding teleconnection patterns (Table 2; Fig. 9). Two Rossby wave source regions are identified (Figs. 1d and 3). Waves can be forced from a source over East Asia and a source in the western portion of the North Pacific. These waves are opposite in phase, as indicated by the source sign and corresponding anomalous Kuroshio anticyclone and North Pacific cyclone (see simplified schematic in Fig. 10). Significant relationships exist between the zonal extent of the west Pacific ITCZ and both sources $(r=0.56$ for the west Pacific source; $r=-0.60$ for the central Pacific 


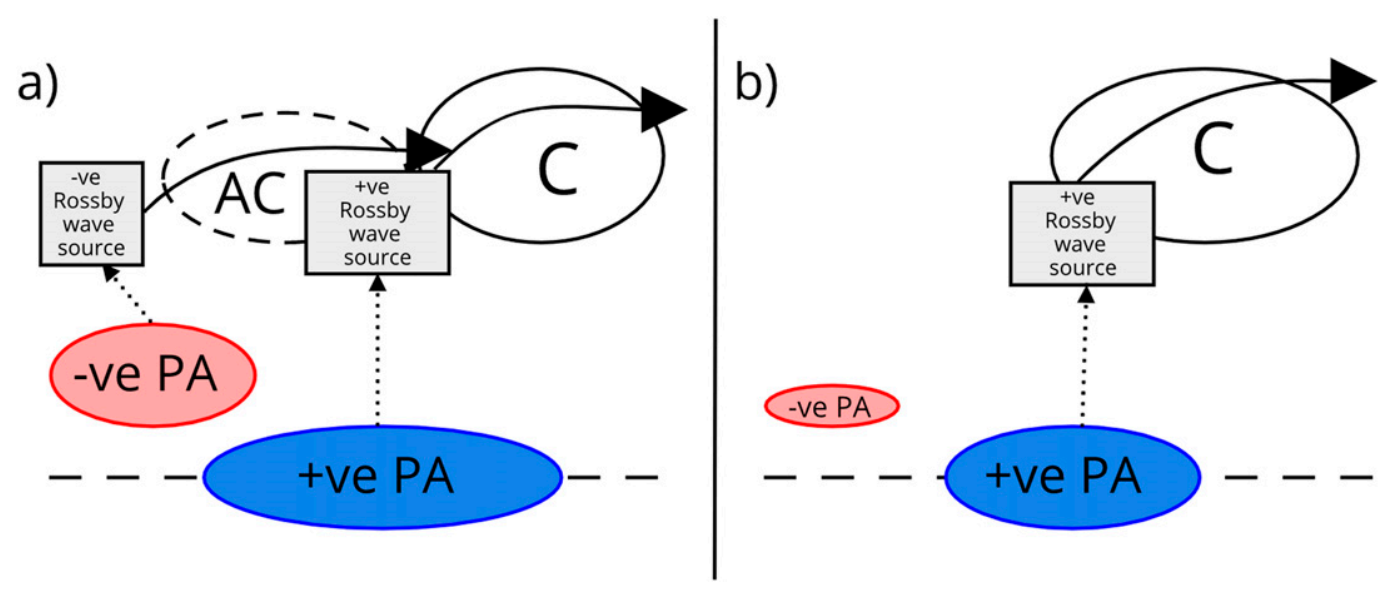

FIG. 10. Simplified schematic showing North Pacific Rossby wave source and cyclone (C) and anticyclone (AC) responses associated with precipitation anomalies (PA) in two cases: (a) a relatively strong western North Pacific negative precipitation anomaly and (b) a relatively weak western North Pacific negative anomaly. Dotted lines indicate the resulting source from a precipitation anomaly. Solid lines indicate northeastward Rossby wave propagation. The North Pacific cyclone can occur in both cases via the positive precipitation anomaly in the west equatorial Pacific, despite the absence of the negative Rossby wave source in the west Pacific.

source), whereas the central Pacific atmospheric mean state shows a linkage only to the central Pacific wave source $(r=0.47)$. Furthermore, relationships are found between these mean-state biases and the strengths of the Kuroshio anticyclone and North Pacific cyclone (Table 2).

When examining the linkage between precipitation responses in various regions of the tropical Pacific during El Niño and the identified Rossby wave sources and corresponding teleconnection patterns, it becomes clear that the teleconnection patterns in the western North Pacific and central Pacific cannot be linked to a single forcing bias. It may be suspected that a bias in the west Pacific forcing can translate to bias in other areas of the teleconnection pattern, such as the North Pacific cyclone, as the Rossby wave propagates northeastward. However, central Pacific atmospheric responses are most strongly linked to the North Pacific cyclone (Table 2). In the absence of the western North Pacific forcing the North Pacific cyclone may still be generated from the central Pacific (see Fig. 10b for simplified schematic), suggesting improvement of biases in both regions should be considered for an accurate teleconnection pattern. This is consistent with a study by Son et al. (2014) in which the western North Pacific anticyclone and the North Pacific cyclone can be generated separately in a linear baroclinic model by forcing the model with only negative precipitation anomalies and only positive precipitation anomalies, respectively.

Here we find that it is possible the teleconnection biases are a result of biases in Rossby wave sources shown in Fig. 3, such that Rossby waves in the WNPweak group are mainly forced from the location of the positive North Pacific wave source and the KAC is reduced as a result. While the two are undoubtedly linked, it is difficult to establish a cause and effect relationship from this study alone. It may be that Rossby wave source biases are a result of differing teleconnection patterns. The direction of this relationship is something to be explored in further study. Similarly, modeling experiments to further explore the role of the mean climate in Rossby wave sources and subsequent ENSO teleconnection patterns are a possible area of future work based on the findings presented here for a multimodel ensemble.

Throughout the course of this study full tropical Pacific mean-state biases in CMIP5 were considered, including North Pacific winds that may affect wave propagation. This study suggests that teleconnection pattern bias is primarily linked to the mean state via forcing of Rossby waves by anomalous precipitation during ENSO events; no strong evidence is found that suggests that other aspects of wave propagation are linked mean-state biases. This is in agreement with a study of seasonal climate predictions that finds little evidence of mean wind bias impacting Rossby wave propagation (Scaife et al. 2017). It should be noted that there is some variance in the ensemble not explained by the relationships discussed here. However, no evidence was found that links the strength of the DJF teleconnection pattern to mean zonal winds in the Pacific (i.e., subtropical jet) or changes in the waveguide over the North Pacific (not shown in figures). Therefore, this 
study suggests that biases in wave propagation play a relatively minor role in teleconnection bias among these models, in comparison to the role of the wave forcing.

This work focuses primarily on the linkage between mean-state bias in coupled climate models and the modeled ENSO teleconnection; it does not explore underlying causes of such mean-state biases. It is also important to note that there is a level of uncertainty in results that is introduced by limited record length; Deser et al. (2017) found that composite analyses of observed ENSO events are subject to significant variance. These are ongoing challenges in climate modeling and assessment of observed and modeled ENSO and should be a high priority for future research in order to improve confidence in model projections of ENSO and its teleconnections.

Acknowledgments. This work was supported by the U.K.-China Research and Innovation Partnership Fund through the Met Office Climate Science for Service Partnership (CSSP) China as part of the Newton Fund. MC acknowledges additional support from the Natural Environment Research Council Grant NE/N018486/1. HLR is supported by China National Science Foundation project (41975094).

\section{REFERENCES}

Adler, R. F., and Coauthors, 2003: The version 2 Global Precipitation Climatology Project (GPCP) Monthly Precipitation Analysis (1979-present). J. Hydrometeor., 4, 1147-1167, https://doi.org/ 10.1175/1525-7541(2003)004<1147:TVGPCP > 2.0.CO;2.

Ashok, K., S. K. Behera, S. A. Rao, H. Weng, and T. Yamagata, 2007: El Niño Modoki and its possible teleconnection. J. Geophys. Res., 112, C11007, https://doi.org/10.1029/2006JC003798.

Bayr, T., M. Latif, D. Dommenget, C. Wengel, J. Harlaß, and W. Park, 2018: Mean-state dependence of ENSO atmospheric feedbacks in climate models. Climate Dyn., 50, 3171-3194, https://doi.org/10.1007/s00382-017-3799-2.

— D. I. V. Domeisen, and C. Wengel, 2019: The effect of the equatorial Pacific cold SST bias on simulated ENSO teleconnections to the North Pacific and California. Climate Dyn. 53, 3771-3789, https://doi.org/10.1007/s00382-019-04746-9.

Bellenger, H., E. Guilyardi, J. Leloup, M. Lengaigne, and J. Vialard, 2014: ENSO representation in climate models: From CMIP3 to CMIP5. Climate Dyn., 42, https://doi.org/ 10.1007/s00382-013-1783-z.

Coats, S., J. E. Smerdon, B. I. Cook, and R. Seager, 2013: Stationarity of the tropical pacific teleconnection to North America in CMIP5/PMIP3 model simulations. Geophys. Res. Lett., 40, 4927 4932, https://doi.org/10.1002/grl.50938.

Dee, D. P., and Coauthors, 2011: The ERA-Interim reanalysis: Configuration and performance of the data assimilation system. Quart. J. Roy. Meteor. Soc., 137, 553-597, https://doi.org/ 10.1002/qj.828.

Deser, C., I. R. Simpson, K. A. McKinnon, and A.S. Phillips, 2017: The Northern Hemisphere extratropical atmospheric circu- lation response to ENSO: How well do we know it and how do we evaluate models accordingly? J. Climate, 30, 5059-5082, https://doi.org/10.1175/JCLI-D-16-0844.1.

Feng J., W. Chen, H. Gong, J. Ying, and W. Jiang, 2018: An investigation of CMIP5 model biases in simulating the impacts of central Pacific El Niño on the East Asian summer monsoon. Climate Dyn., 52, 2631-2646, https://doi.org/10.1007/S00382018-4284-2.

Ferrett, S., and M. Collins, 2016: ENSO feedbacks and their relationships with the mean state in a flux adjusted ensemble. Climate Dyn., 52, 7189-7208, https://doi.org/10.1007/S00382016-3270-9.

, - — , and H.-L. Ren, 2017: Understanding bias in the evaporative damping of El Niño-Southern Oscillation events in CMIP5 models. J. Climate, 30, 6351-6370, https://doi.org/ 10.1175/JCLI-D-16-0748.1.

,-- , and - 2018: Diagnosing relationships between mean state biases and El Niño shortwave feedback in CMIP5 models. J. Climate, 31, 1315-1335, https://doi.org/10.1175/ JCLI-D-17-0331.1.

Giannini, A., Y. Kushnir, and M. A. Cane, 2000: Interannual variability of Caribbean rainfall, ENSO, and the Atlantic Ocean. J. Climate, 13, 297-311, https://doi.org/10.1175/1520-0442(2000) 013<0297:IVOCRE > 2.0.CO;2.

Ham, Y., and J. Kug, 2015: Improvement of ENSO simulation based on intermodel diversity. J. Climate, 28, 998-1015, https:// doi.org/10.1175/JCLI-D-14-00376.1.

Horel, J. D., and J. M. Wallace, 1981: Planetary-scale atmospheric phenomena associated with the Southern Oscillation. Mon. Wea. Rev., 109, 813-829, https://doi.org/10.1175/1520-0493(1981) 109<0813:PSAPAW > 2.0.CO;2.

Kim, J.-W., S.-I. An, S.-Y. Jun, H.-J. Park, and S.-W. Yeh, 2017: ENSO and East Asian winter monsoon relationship modulation associated with the anomalous northwest Pacific anticyclone. Climate Dyn., 49, 1157-1179, https://doi.org/10.1007/ s00382-016-3371-5.

Kim, S., H.-Y. Son, and J.-S. Kug, 2017: How well do climate models simulate atmospheric teleconnections over the North Pacific and East Asia associated with ENSO? Climate Dyn., 48, 971-985, https://doi.org/10.1007/s00382-016-3121-8.

Kim, S. T., W. Cai, F.-F. Jin, and J.-Y. Yu, 2013: ENSO stability in coupled climate models and its association with mean state. Climate Dyn., 42, 3313-3321, https://doi.org/10.1007/s00382013-1833-6.

Klein, S. A., B. J. Soden, and N.-C. Lau, 1999: Remote sea surface temperature variations during ENSO: Evidence for a tropical atmospheric bridge. J. Climate, 12, 917-932, https://doi.org/ 10.1175/1520-0442(1999)012<0917:RSSTVD > 2.0.CO 2 .

Kug, J.-S., M.-S. Ahn, M.-K. Sung, S.-W. Yeh, H.-S. Min, and Y.-H. Kim, 2010: Statistical relationship between two types of El Niño events and climate variation over the Korean Peninsula. Asia-Pac. J. Atmos. Sci., 46, 467-474, https://doi.org/10.1007/ s13143-010-0027-y.

Li, T., B. Wang, B. Wu, T. Zhou, C.-P. Chang, and R. Zhang, 2017: Theories on formation of an anomalous anticyclone in Western North Pacific during El Niño: A review. J. Meteor. Res., 31, 9871006, https://doi.org/10.1007/s13351-017-7147-6.

Liren, J., S. Sun, K. Arpe, and L. Bengtsson, 1997: Model study on the interannual variability of Asian winter monsoon. Adv. Atmos. Sci., 14, 1-22, https://doi.org/10.1007/s00376-997-0039-4.

Pennell, C., and T. Reichler, 2011: On the effective number of climate models. J. Climate, 24, 2358-2367, https://doi.org/ 10.1175/2010JCLI3814.1. 
Perry, S. J., S. McGregor, A. S. Gupta, and M. H. England, 2017: Future changes to El Niño-Southern Oscillation temperature and precipitation teleconnections. Geophys. Res. Lett., 44, 10 608-10 616, https://doi.org/10.1002/2017GL074509.

Rayner, N. A., D. E. Parker, E. B. Horton, C. K. Folland, L. V. Alexander, D. P. Rowell, E. C. Kent, and A. Kaplan, 2003: Global analyses of sea surface temperature, sea ice, and night marine air temperature since the late nineteenth century. J. Geophys. Res., 108, 4407, https://doi.org/10.1029/2002JD002670.

Sardeshmukh, P., and B. J. Hoskins, 1988: The generation of global rotational flow by steady idealized tropical divergence. J. Atmos. Sci. 45, 1228-1251, https://doi.org/10.1175/1520-0469(1988)045<1228: TGOGRF $>2.0 . \mathrm{CO} ; 2$.

Scaife, A. A., and Coauthors, 2017: Tropical rainfall, Rossby waves and regional winter climate predictions. Quart. J. Roy. Meteor. Soc., 143, 1-11, https://doi.org/10.1002/qj.2910.

Son, H.-Y., J.-Y. Park, J.-S. Kug, J. Yoo, and C.-H. Kim, 2014: Winter precipitation variability over Korean Peninsula associated with ENSO. Climate Dyn., 42, 3171-3186, https:// doi.org/10.1007/s00382-013-2008-1.

Song, F., and T. Zhou, 2014: The climatology and interannual variability of East Asian summer monsoon in CMIP5 coupled models: Does air-sea coupling improve the simulations? J. Climate, 27, 8761-8777, https://doi.org/10.1175/JCLI-D-14-00396.1.

Takaya, K., and H. Nakamura, 2001: A formulation of a phaseindependent wave-activity flux for stationary and migratory quasigeostrophic eddies on a zonally varying basic flow. J. Atmos. Sci., 58, 608-627, https://doi.org/10.1175/15200469(2001)058<0608:AFOAPI > 2.0.CO;2.

Taylor, K. E., R. J. Stouffer, and G. A. Meehl, 2012: An overview of CMIP5 and the experiment design. Bull. Amer. Meteor. Soc., 93, 485-498, https://doi.org/10.1175/BAMS-D-11-00094.1.

Tomita, T., and T. Yasunari, 1996: Role of the northeast winter monsoon on the biennial oscillation of the ENSO/monsoon system. J. Meteor. Soc. Japan, 74, 399-413, https://doi.org/10.2151/jmsj1965.74.4_399.

Wallace, J. M., and D. S. Gutzler, 1981: Teleconnections in the geopotential height field during the Northern Hemisphere winter. Mon. Wea. Rev., 109, 784-812, https://doi.org/10.1175/ 1520-0493(1981)109<0784:TITGHF>2.0.CO;2.

Wang, B., and J. C. L. Chan, 2002: How strong ENSO events affect tropical storm activity over the western North Pacific. J. Climate,
15, 1643-1658, https://doi.org/10.1175/1520-0442(2002)015<1643: HSEEAT $>2.0 . \mathrm{CO} ; 2$.

_, $\mathrm{R}$. Wu, and X. Fu, 2000: Pacific-East Asian teleconnection: How does ENSO affect East Asian climate? J. Climate, 13, 1517-1536, https://doi.org/10.1175/1520-0442(2000)013<1517: PEATHD $>2.0$.CO;2.

Wang, P., C. Tam, and K. Xu, 2019: El Niño-East Asian monsoon teleconnection and its diversity in CMIP5 models. Climate Dyn., 53, 6417-6435, https://doi.org/10.1007/s00382-01904938-3.

Weare, B. C., 2013: El Niño teleconnections in CMIP5 models. Climate Dyn., 41, 2165-2177, https://doi.org/10.1007/s00382012-1537-3.

Wu, B., T. Zhou, and T. Li, 2009: Seasonally evolving dominant interannual variability modes of East Asian climate. J. Climate, 22, 2992-3005, https://doi.org/10.1175/2008JCLI2710.1.

,-- , and - 2017: Atmospheric dynamic and thermodynamic processes driving the western North Pacific anomalous anticyclone during El Niño. Part II: Formation processes. J. Climate, 30, 9637-9650, https://doi.org/10.1175/JCLI-D-160495.1.

Xie, S.-P., K. Hu, J. Hafner, H. Tokinaga, Y. Du, G. Huang, and T. Sampe, 2009: Indian Ocean capacitor effect on Indowestern Pacific climate during the summer following El Niño. J. Climate, 22, 730-747, https://doi.org/10.1175/ 2008JCLI2544.1.

Zhang, R., A. Sumi, and M. Kimoto, 1996: Impact of El Niño on the East Asian monsoon: A diagnostic study of the '86/87 and '91/ 92 events. J. Meteor. Soc. Japan, 74, 49-62, https://doi.org/ 10.2151/jmsj1965.74.1_49.

,-- , and 1999: A diagnostic study of the impact of El Niño on the precipitation in China. Adv. Atmos. Sci., 16, 229241, https://doi.org/10.1007/BF02973084.

Zhang, W., H. Li, M. F. Stuecker, F. Jin, and A. G. Turner, 2016a: A new understanding of El Nino's impact over East Asia: Dominance of the ENSO combination mode. J. Climate, 29, 4347-4359, https://doi.org/10.1175/JCLI-D-15-0104.1.

— East Asian Monsoon and Yangtze River summer flooding. Geophys. Res. Lett., 43, 11375-11382, https://doi.org/10.1002/ 2016GL071190. 